\title{
Debromination of hexabromobenzene by its co-grinding with $\mathrm{CaO}$
}

\author{
Qiwu Zhang ${ }^{\text {a,* }}$, Hiroki Matsumoto ${ }^{\text {a }}$, Fumio Saito ${ }^{\text {a }}$, Michel Baron ${ }^{b}$ \\ a Institute of Multidisciplinary Research for Advanced Materials (IMRAM), Tohoku University, 2-1-1 Katahira, \\ Aoba-ku, Sendai 980-8577, Japan \\ ${ }^{\mathrm{b}}$ Ecole des Mines d'Albi-Carmauz, UMR CNRS-2392, 81013 Albi, France
}

\begin{abstract}
A hexabromobenzene ( $\mathrm{HBB}, \mathrm{C}_{6} \mathrm{Br}_{6}$ ) powder was subjected to co-grinding with excess $\mathrm{CaO}$ powder in air using a planetary ball mill to investigate mechanochemical debromination of the HBB sample. The reaction proceeds smoothly with an increase in both grinding time and molar ratio of $\mathrm{CaO}$ addition. The co-grinding enables us to debrominate HBB, forming $\mathrm{CaBr}_{2}, \mathrm{C}$ and $\mathrm{CaCO}_{3}$ besides excess $\mathrm{CaO}$ in the product. $\mathrm{CaBr}_{2}$ in the product tends to absorb moisture from the atmosphere to form $\mathrm{CaBr}_{2} \cdot n \mathrm{H}_{2} \mathrm{O}$. The reaction yield is quantitatively evaluated by measuring the amount of water-soluble bromide through water washing and the amount of unreacted HBB through toluene washing. It is found that almost $100 \%$ of debromination is achieved by $6 \mathrm{~h}$ grinding with the molar ratio kept constant at 2:1. Radicals are detected in the ground products, possibly due to rupture in the covalent bonds of $\mathrm{C}-\mathrm{C}$ and $\mathrm{C}-\mathrm{Br}$ in $\mathrm{HBB}$.
\end{abstract}

Keywords: HBB; Fire retardant; Mechanochemistry; Bromide; Radical

\section{Introduction}

Once polymers containing halogen are subjected to heating in air, halide hydrogen is normally generated, which acts effectively to dilute flammable gases and finally to cease the cascading radical reaction. These polymers are called, therefore, as fire retardant materials, which reduce the degree of flame spread over a surface and afford protection to an underlying substrate. They act also as a buffer between a flammable substrate and any source of ignition. Such property enables us to use in wide applications such as circuit boards in electric devices, commodities in heating devices and a like. They

${ }^{*}$ Corresponding author. Tel.: +81-22-217-5137; fax: +81-22217-5137.

E-mail address: zhangqw@tagen.tohoku.ac.jp (Q. Zhang). are generally categorized into two groups; one is chloride group and the other bromide one. Especially, the latter group is of superior effect as a fire retardant to the former one, due to lower dissociation energy for $\mathrm{C}-\mathrm{Br}$ bond than that for $\mathrm{C}-\mathrm{Cl}$ bond. A representative compound of the bromine group is hexabromobenzene $\left(\mathrm{HBB}, \mathrm{C}_{6} \mathrm{Br}_{6}\right.$ ), of which production amount has increased year by year. Accordingly, the amount of HBB wastes is in accordance with the production amount, leading to increment of the wastes. They have been normally subjected to combustion in waste treatment facilities, where toxic gases such as $\mathrm{HBr}$ and highly toxic compounds like polybrominated dioxins, although small amount, are generated (Bindra and Narang, 1995, 1996; Wanke et al., 1996; Weber and Greim, 1997), causing pollution and contamination of environment. In order to avoid such defects, various methods to debrominate the waste have been proposed, which involve the uses of chemicals agents with aid of specific treatments such 
as ultrasound, photolysis, catalysis et al. (Khurana and Sehgal, 1996; Mackenzie and Kopinke, 1996; Hall et al., 1997; Atobe et al., 1998; Bedard and Van Dort, 1998; Wei and Hor, 1998). These methods are unique and excellent, however, they are generally difficult to operate and require uses of specific expensive reagents and/or devices. The authors have proposed a novel simple method to decompose organic polymer wastes containing halogens such as $\mathrm{F}, \mathrm{Cl}$ by means of mechanochemical (MC) treatment, namely co-grinding with inorganic additives (Zhang 1999, 2001a,b). The halogens in the polymers can be transformed into inorganic phases such as $\mathrm{Sr} / \mathrm{Ca}$ fluoride or chloride through the MC solid reactions even at room temperature. The authors have applied this method to the debromination of bromine polymer waste of $\mathrm{HBB}$, which has an aromatic structure, different from the above polymers.

The main purpose of this paper is to provide basic information on MC debromination of HBB by grinding with $\mathrm{CaO}$ in air. This work offers a novel process to debrominate flame retardants. It also allow us to investigate comparatively the mechanism of $\mathrm{MC}$ decomposition of aromatic structures, on which the authors have been working recently (Ikoma et al., 2001; Zhang et al., 2001c).

\section{Experimental}

\subsection{Samples and experimental procedure}

A HBB sample was supplied from Sumitomo Bakelite Co. Ltd., Japan. A CaO sample was prepared by heating $\mathrm{Ca}(\mathrm{OH})_{2}$, which was obtained from Wako Pure Chemicals Ltd., Japan, at $1000{ }^{\circ} \mathrm{C}$ for $2 \mathrm{~h}$ in an oven. HBB and $\mathrm{CaO}$ samples were mixed at different molar ratio of $\mathrm{Ca}$ to $\mathrm{Br}$ in the mixtures, which were used as a starting sample. The starting sample was subjected to grinding in air, then the ground sample was washed with distilled water to separate soluble compounds formed mechanochemically during grinding by filtration. These operations as well as characterizations were described in detail below.

\subsection{Grinding and washing}

A planetary mill (Pulverisette-7, Fritsch, Germany) was used for grinding the mixture. The mill consists of a pair of pots made of zirconia and a rotating disc. Two grams of the mixture was put in the zirconia pot $\left(45 \mathrm{~cm}^{3}\right.$ inner volume) with seven zirconia balls of $15 \mathrm{~mm}$ diameter and subjected to grinding in air at $700 \mathrm{rpm}$ speed for various periods of time.

\subsection{Characterization}

The ground mixtures were characterized as follows: X-ray diffraction (XRD) analysis was conducted by using a diffractometer (RAD-B, Rigaku, Japan) with $\mathrm{Cu}-\mathrm{K} \alpha$ radiation to identify the phases formed in the ground products as well as the washed ones. Thermogravimetric analysis (TG) was performed for the samples by using a TG/DTA analyzer (TAS-200, Rigaku Denki, Japan) at $5 \mathrm{~K} / \mathrm{min}$ of heating rate in air. FT-IR analysis was taken for the samples by means of Fourier transform infrared (FT-IR) spectroscopy using a $\mathrm{KBr}$ disc method. ESR spectrometer (X-band, 9.6 GHz, Bruker ESR-380E) was also used to detect radicals in the ground samples. The filtrate was characterized by an ion chromatography (LC10 series, Shimadzu, Japan) to determine the ion type and its concentration.

\subsection{Confirmation of the formed compound and reaction yield}

The ground mixtures were dispersed in distilled water to dissolve soluble compounds formed during grinding, then the filtrate was dried in an oven to form solid powder. In order to confirm a compound formed in the ground mixture, a chemical reagent, $\mathrm{CaBr}_{2} \cdot 2 \mathrm{H}_{2} \mathrm{O}$ sample was used as a reference. Two methods for determining the reaction yield were employed: One is a toluene washing, where unreacted HBB sample remaining in the product dissolves. The amount of the remaining $\mathrm{HBB}$ after evaporating the toluene solvent was weighed. For comparison, water washing was conducted to dissolve $\mathrm{CaBr}_{2}$ formed in the product. The concentrate of $\mathrm{Br}$ anion in the filtrate was measured by IC analysis. The degree to which the MC reaction proceeds were quantitatively evaluated by calculating the percentage of the reacted HBB and the soluble bromide, respectively.

\section{Results and discussion}

\subsection{Effect of $\mathrm{CaO}$ amount in mechanochemical reaction}

Fig. 1 shows XRD patterns of $4 \mathrm{~h}$ ground mixtures, which has been prepared by changing the amount of $\mathrm{CaO}$ from $1: 2$ to $2: 1$ in molar ratio of $\mathrm{Ca}$ to $\mathrm{Br}$. The molecular ratio of $1: 2$ for $\mathrm{Ca}: \mathrm{Br}$ in the mixture was set for stoichiometric generation of $\mathrm{CaBr}_{2}$. Several small peaks corresponding to $\mathrm{HBB}$ are still observed in two patterns with $\mathrm{Ca}: \mathrm{Br}$ addition ratios of $1: 2$ and $1: 1$, respectively. The peaks of HBB has disappeared when the addition ratio of $\mathrm{Ca}: \mathrm{Br}$ is increased to $3: 2$ or more (2:1). These results indicate that $\mathrm{HBB}$ has been decomposed 


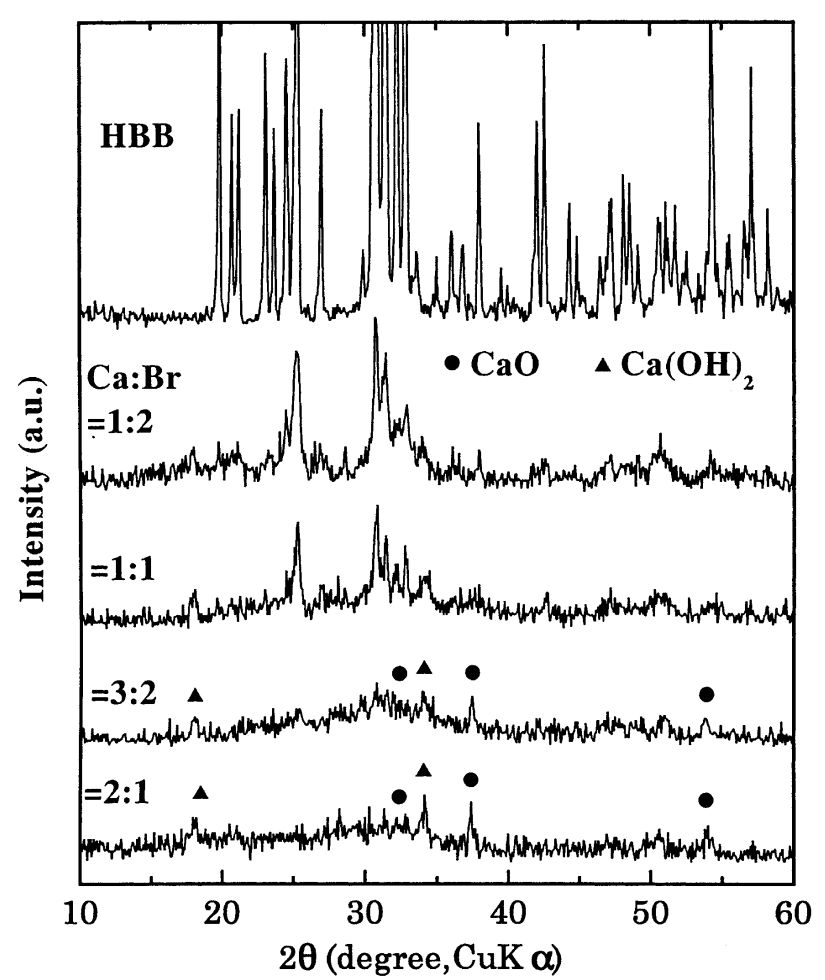

Fig. 1. XRD patterns of the original $\mathrm{HBB}$ and the $4 \mathrm{~h}$ ground samples with different molar ratios of $\mathrm{Ca}: \mathrm{Br}$.

efficiently by adding $\mathrm{CaO}$ in molar ratio more than 1:1. Unfortunately, there are no new peaks observable in the patterns, suggesting the formed products in the ground sample are somehow amorphous in crystalline state. There exist some weak peaks of $\mathrm{CaO}$, which is added in extra amount based on the stoichiometric molar ratio of $\mathrm{CaBr}_{2}$, and of $\mathrm{Ca}(\mathrm{OH})_{2}$, which is formed through the water absorption of unreacted $\mathrm{CaO}$. Fig. 2 shows TG curves of the $4 \mathrm{~h}$ ground mixtures, which are the same ones as that shown in Fig. 1. Weight loss due to the combustion of $\mathrm{HBB}$ at around $250^{\circ} \mathrm{C}$ is observed with $\mathrm{Ca}$ added in $1: 2$ to $\mathrm{Br}$, confirming that $\mathrm{HBB}$ is still remaining after grinding, consistent with the result by XRD analysis shown in Fig. 1. However, the value of the weight loss tends to decrease with an increase in the molar ratio of $\mathrm{Ca}$ to $\mathrm{Br}$ in the mixtures and there is no weight loss observed in the case of $2: 1$ for $\mathrm{Ca}: \mathrm{Br}$. The results indicate clearly that the increase in molar ratio of $\mathrm{CaO}$ addition facilitates the decomposition of HBB by grinding and two times of $\mathrm{Ca}$ to $\mathrm{Br}$ is required to break HBB completely. On the other hand, the weight loss, which is attributed to thermal decomposition of reaction products, is observed in the temperature range from around 600 to $780{ }^{\circ} \mathrm{C}$. The much higher temperature at which the reaction products decompose implies that they are more stable than HBB itself. These reaction products are inorganic rather than organic ones. Both $\mathrm{C}$ and $\mathrm{Br}$ in

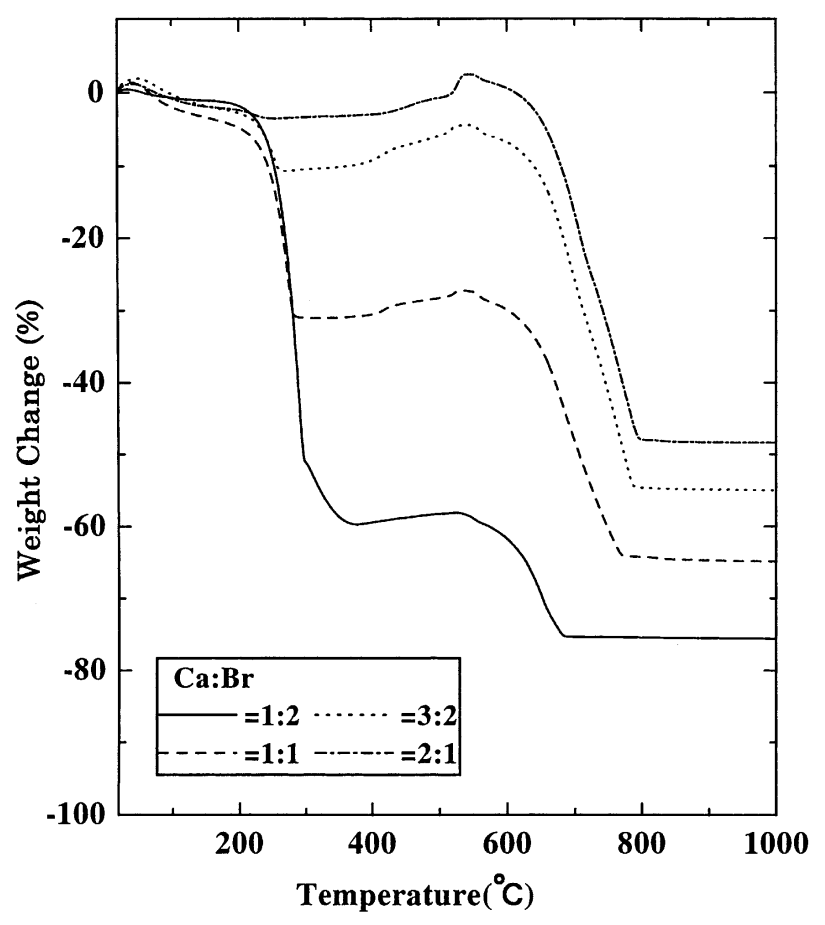

Fig. 2. TG curves of the $4 \mathrm{~h}$ ground samples with different molar ratio of $\mathrm{Ca}: \mathrm{Br}$.

HBB have been transformed and fixed in inorganic phases, of which the composition will be discussed in later session. Value of weight loss increases with an increase in the amount ratio of $\mathrm{Ca}$ to $\mathrm{Br}$ in the samples. Taking the results by XRD analysis and TG analysis into account, the mixture having the molar ratio of 2:1 for $\mathrm{Ca}: \mathrm{Br}$ would be suitable for the starting sample to facilitate the MC reaction. Therefore, it was fixed as 2:1 hereinafter experiment.

\subsection{Effect of grinding time in the mechanochemical reaction}

Fig. 3 shows XRD patterns of the mixture ground for different periods of time. The peak intensity of HBB is drastically lowered within $1 \mathrm{~h}$ grinding, suggesting that the $\mathrm{MC}$ reaction proceeds quickly by the co-grinding. However, some small peaks of HBB still exist in the pattern of the sample ground for $2 \mathrm{~h}$. These peaks have disappeared for the sample ground for $3 \mathrm{~h}$ or more, indicating $3 \mathrm{~h}$ grinding is required to decomposing $\mathrm{HBB}$ completely, while results of the practical quantitative analysis are provided in the later session. Peaks of $\mathrm{CaO}$ sample remain in all the patterns because of the extra addition.

Fig. 4 shows TG curves of the mixtures ground for different periods of time. Significant weight loss around $250-300{ }^{\circ} \mathrm{C}$ due to $\mathrm{HBB}$ combustion can be seen for the 


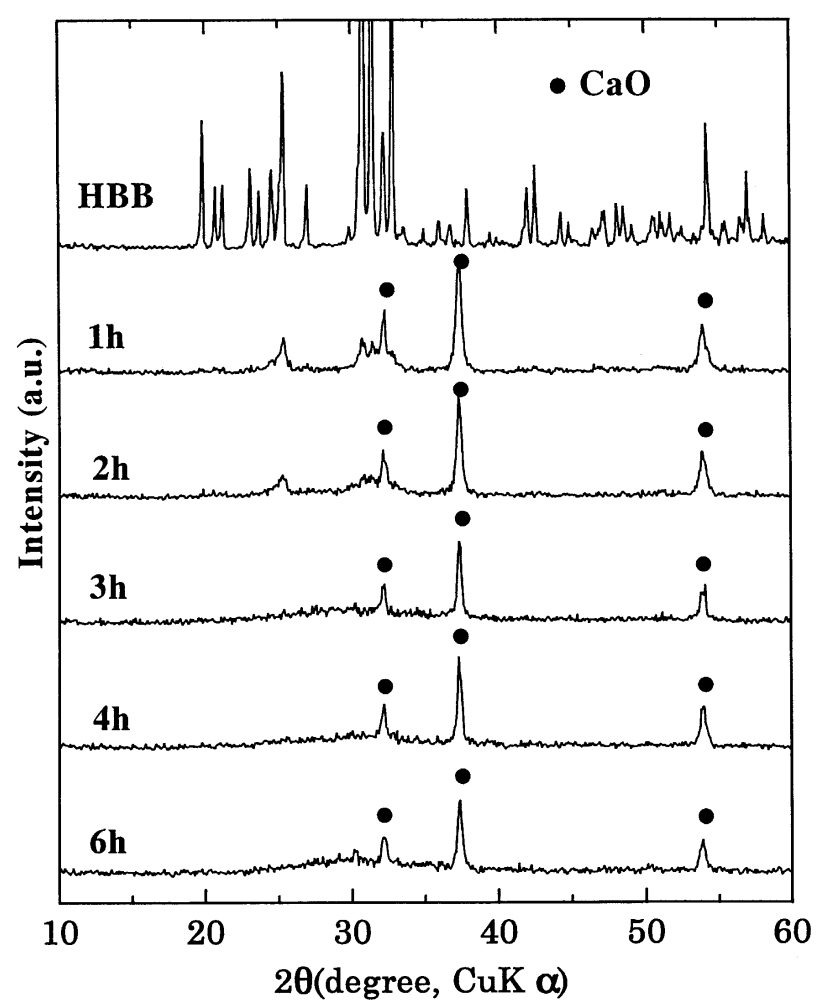

Fig. 3. XRD patterns of the original $\mathrm{HBB}$ and the mixed sample $(\mathrm{Ca}: \mathrm{Br}=2: 1)$ ground for different periods of time.

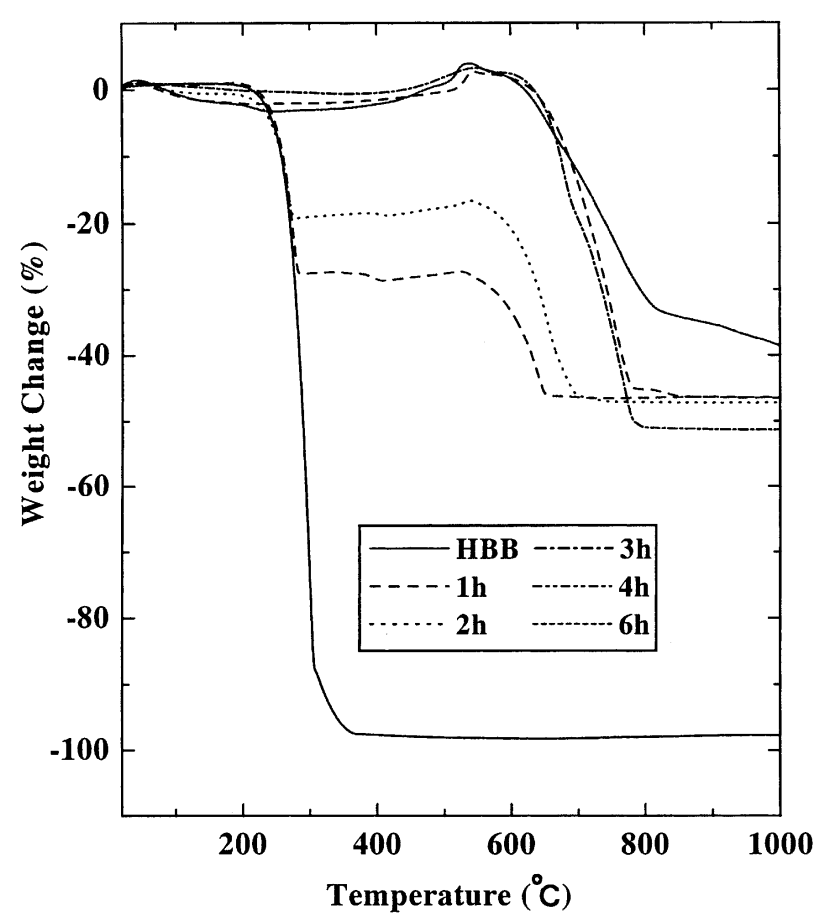

Fig. 4. TG curves of the original $\mathrm{HBB}$ and the mixed sample $(\mathrm{Ca}: \mathrm{Br}=2: 1)$ ground for different periods of time.

mixtures ground for 1 and $2 \mathrm{~h}$, and their values are measured as 30 and $20 \mathrm{wt} \%$, respectively. However, there is not any significant change in the curves of the mixtures ground for $3 \mathrm{~h}$ or more in the same temperature range as above up to $550{ }^{\circ} \mathrm{C}$, indicating that the HBB sample is decomposed completely by grinding for $3 \mathrm{~h}$ or more, the results consistent with that by XRD analysis shown in Fig. 3. One the other hand, new weight loss is observed around temperature range from 600 to $780{ }^{\circ} \mathrm{C}$, due to the products formed by the grinding, which is similar to that shown in Fig. 2. Its value increases correspondingly with an increase in grinding time, suggesting that the $\mathrm{MC}$ reaction proceeds with an increase in grinding time.

Fig. 5 shows FT-IR spectra of the mixture ground for different periods of time together with that of the pure HBB sample. Peaks positioned around $1400 \mathrm{~cm}^{-1}$ due to benzene mode and peak around $600 \mathrm{~cm}^{-1}$ due to $\mathrm{C}-\mathrm{Br}$ stretching vibration appear in the spectrum of $\mathrm{HBB}$ sample, and these peaks have been still observed in the spectrum of the mixture ground for $2 \mathrm{~h}$. However, the peaks have disappeared from the spectra of the mixtures ground for $4 \mathrm{~h}$ or more. These results indicate that grinding over $4 \mathrm{~h}$ has cut the $\mathrm{C}-\mathrm{Br}$ bonding and broken the benzene ring completely. A sharp peak appears in the ground mixtures at around $900 \mathrm{~cm}^{-1}$, which is attributed to the $\mathrm{C}-\mathrm{O}$ stretching vibration. In addition, new peaks due to the $\mathrm{C}-\mathrm{O}$ binding can be seen in the all spectra of the ground mixtures at around $1500 \mathrm{~cm}^{-1}$,

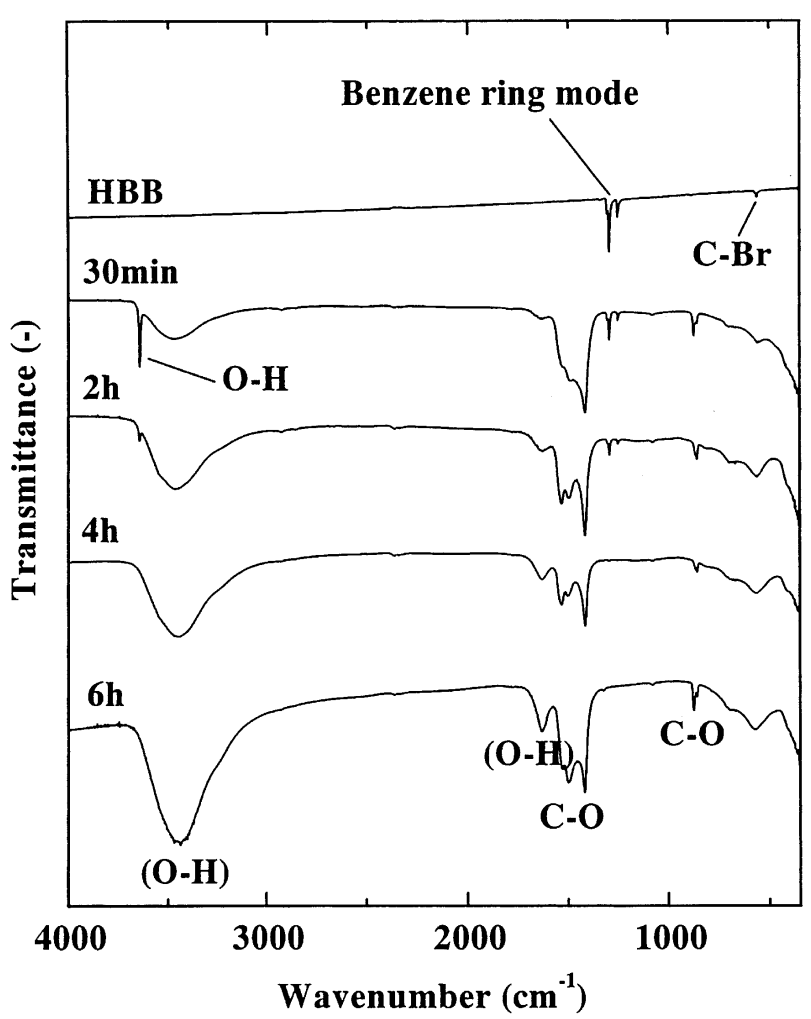

Fig. 5. FT-IR spectra of the original HBB and the mixed sample $(\mathrm{Ca}: \mathrm{Br}=2: 1)$ ground for different periods of time. 


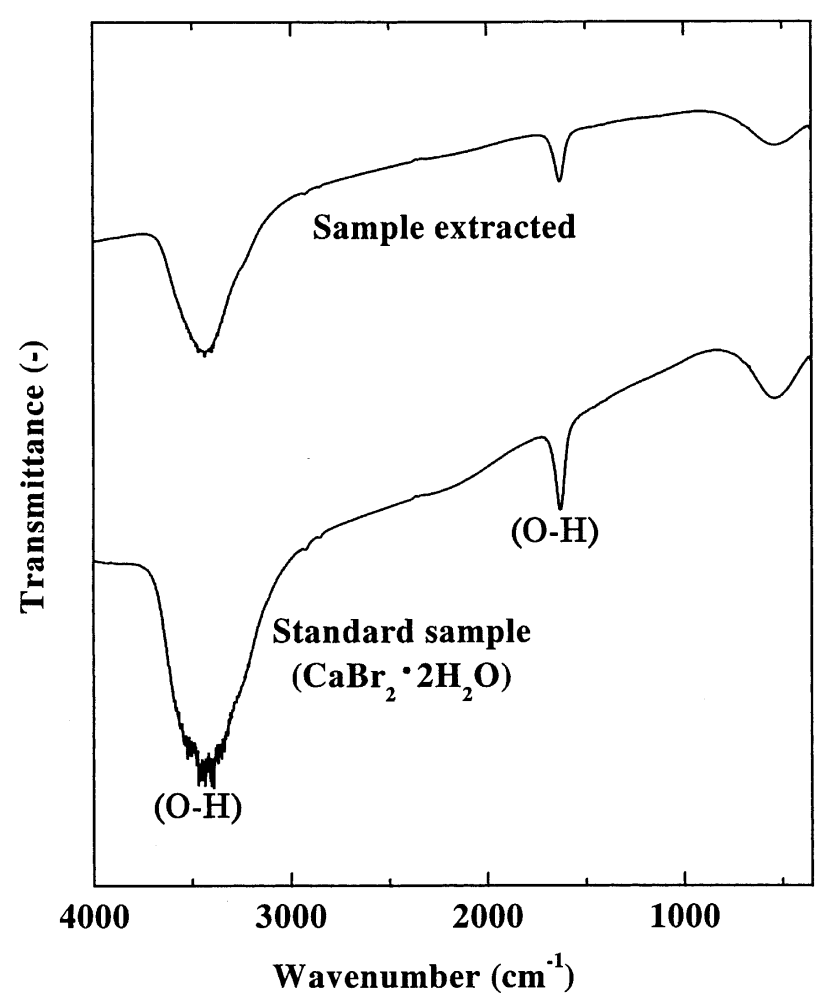

Fig. 6. FT-IR spectra of the standard $\mathrm{CaBr}_{2} \cdot 2 \mathrm{H}_{2} \mathrm{O}$ and the reaction product extracted by water from the ground sample.

suggesting the existence of $\mathrm{CaCO}_{3}$ in the product. Peaks due to $\mathrm{O}-\mathrm{H}$ binding can also be seen in the all spectra of the ground mixtures at around 1650 and $3500 \mathrm{~cm}^{-1}$, and their peak intensities tend to increase as grinding progresses. This suggests the presence of water in the product. Fig. 6 shows FT-IR spectrum of the standard $\mathrm{CaBr}_{2} \cdot 2 \mathrm{H}_{2} \mathrm{O}$ sample together with that of a solid powder sample, which was prepared from the $6 \mathrm{~h}$ ground mixture by the extraction with distilled water followed by drying procedure. As can be seen in the figure, the spectrum of the solid powder sample is quite similar to that of the standard $\mathrm{CaBr}_{2} \cdot 2 \mathrm{H}_{2} \mathrm{O}$ sample, implying that the solid should be $\mathrm{Ca}$ bromide hydrated $\left(\mathrm{CaBr}_{2} \cdot n \mathrm{H}_{2} \mathrm{O}\right)$. Therefore, the co-grinding of the mixture allows transformation of bromine from HBB into inorganic $\mathrm{CaBr}_{2}$, which adsorbs moisture from the environment to form $\mathrm{CaBr}_{2} \cdot n \mathrm{H}_{2} \mathrm{O}$. Accompanied by the $\mathrm{Ca}-\mathrm{Br}$ bonding, the carbon in HBB might be bound to oxygen in $\mathrm{CaO}$ to form $\mathrm{CO}$ gas (Zhang et al., 2001a). However, the extra addition of $\mathrm{CaO}$ has led to different products. Formation of $\mathrm{Ca}$ carbonate is observed. Another is free carbon, which is confirmed indirectly from the color change. The white color of the starting powders has changed gradually into black with an increase in grinding time and samples ground over $3 \mathrm{~h}$ are found to be in deep black. Both $\mathrm{Ca}$ carbonate and bromide will decompose around $600-800{ }^{\circ} \mathrm{C}$, consistent with the results by TG analysis shown in Figs. 2 and 4. The reaction induced by grinding may be described as follows:

$$
\begin{aligned}
\mathrm{C}_{6} \mathrm{Br}_{6} & +12 \mathrm{CaO}+3 n \mathrm{H}_{2} \mathrm{O} \\
\rightarrow & 3 \mathrm{CaBr}_{2} \cdot n \mathrm{H}_{2} \mathrm{O}+(3 / 2) \mathrm{CaCO}_{3} \\
& +(15 / 2) \mathrm{CaO}+(9 / 2) \mathrm{C}
\end{aligned}
$$

\subsection{Quantitative measurement of mechanochemical reac- tion yield}

Fig. 7 shows the reaction yield determined by the two methods described in the experimental section as a function of grinding time. It is worth mentioning that the two curves are well consistent, and the reaction proceeds smoothly in the early stage of grinding, and subsequently the reaction rate levels off. Its yield reaches about $90 \%$ at $3 \mathrm{~h}$ and almost $100 \%$ at $6 \mathrm{~h}$ grinding. This means that the HBB sample tends to degrade gradually with an increase in grinding time and almost finishes up to $6 \mathrm{~h}$ grinding. Fig. 8 shows ESR spectra of the mixtures ground for different periods of time. It is clearly indicated that radical signal is detected in all ground mixtures at around $3420 \mathrm{G}$, its intensity tends to increase generally as the grinding operation progresses. However, the intensity for the $6 \mathrm{~h}$ ground mixture is slightly

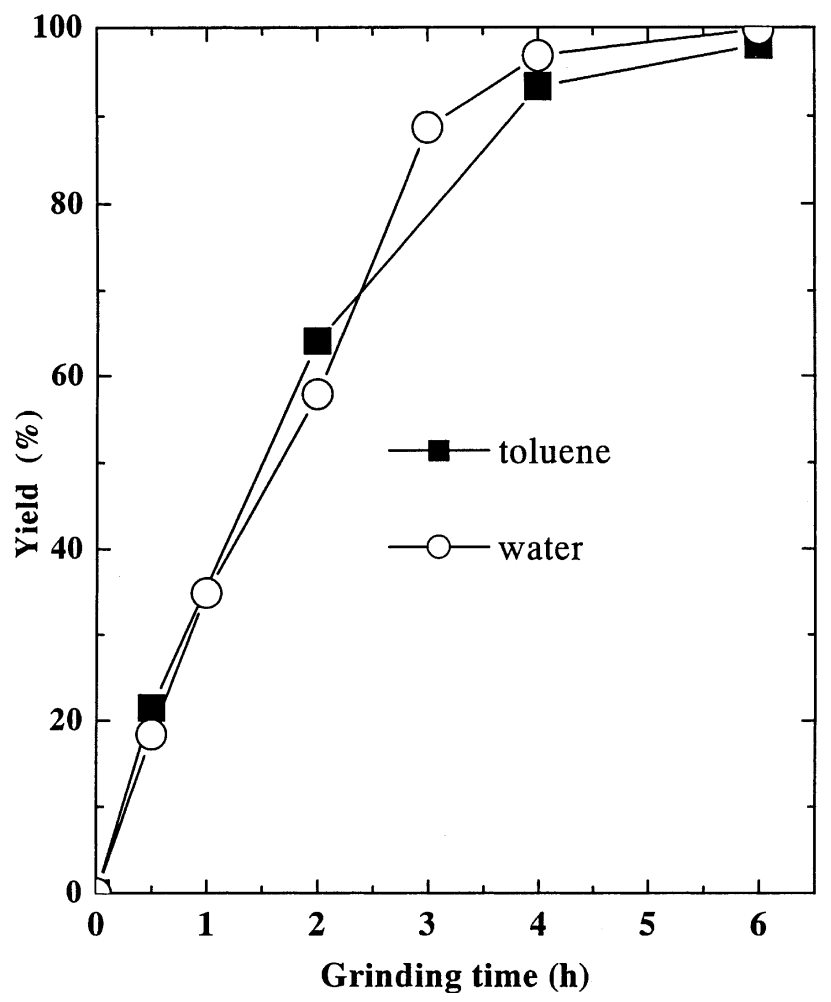

Fig. 7. Change in the yields of soluble bromide and reacted HBB with grinding time. 


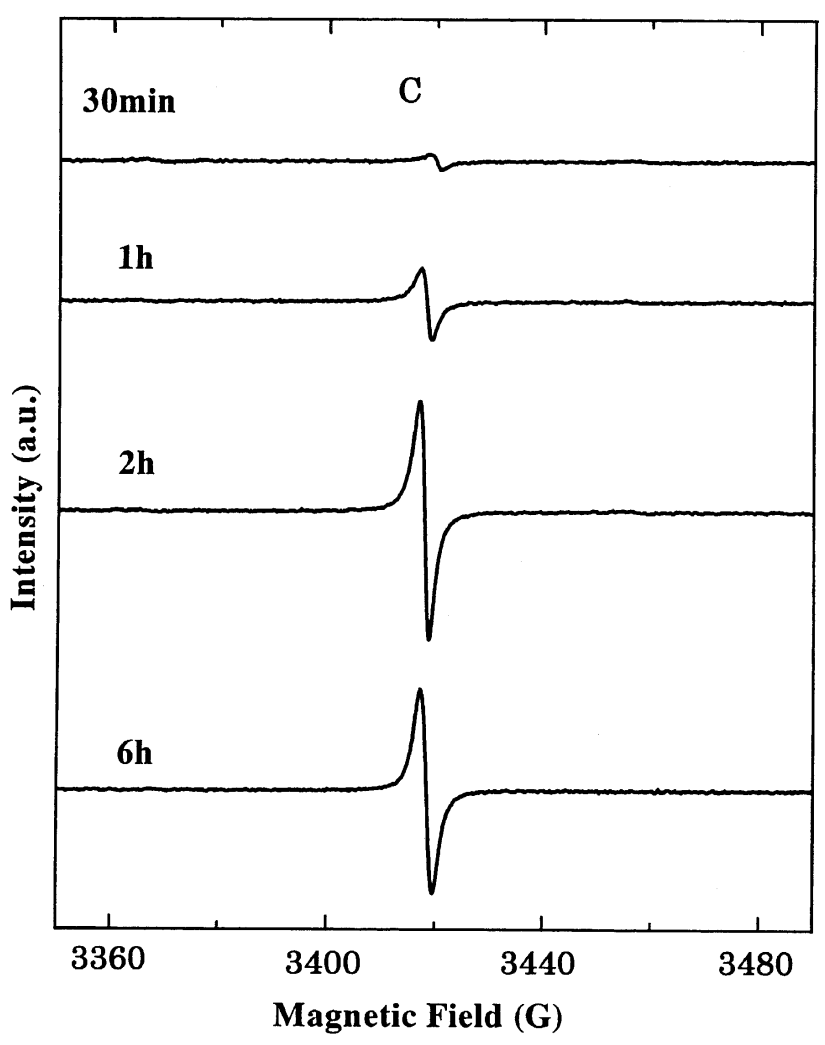

Fig. 8. ESR spectra of the sample ground for different periods of time.

weaker than that of the $2 \mathrm{~h}$ one. The radical generation could be attributed to the free carbon formation (Ikoma et al., 1998a,b; Raffi et al., submitted for publication) due to the breakage phenomena in HBB structure. Further investigation about the characterization of the carbon composition and the relation of its formation with radical occurrence is under consideration.

\section{Conclusion}

HBB powder sample was mixed with a chemical reagent, $\mathrm{CaO}$ powder at different molar ratio, then the mixture was subjected to grinding in air using the planetary ball mill to investigate the $\mathrm{MC}$ reaction to debrominate HBB sample. The experimental results are summarized as follows:

(1) Excess $\mathrm{CaO}$ sample plays a significant role to facilitate the solid reaction and to avoid gas generation during the grinding.

(2) The reaction between $\mathrm{HBB}$ and $\mathrm{CaO}$ proceeds smoothly when the $\mathrm{CaO}$ sample is added to the $\mathrm{HBB}$ at molar ratio of 2:1 for $\mathrm{Ca}: \mathrm{Br}$. The co-grinding enables us to debrominate $\mathrm{HBB}$, forming $\mathrm{CaBr}_{2}$, $\mathrm{C}$ and $\mathrm{CaCO}_{3}$ besides excess $\mathrm{CaO}$ in the product.
(3) $\mathrm{CaBr}_{2}$ in the product tends to adsorb moisture from the atmosphere to form $\mathrm{CaBr}_{2} \cdot n \mathrm{H}_{2} \mathrm{O}$. The reaction yield is increased with an increase in grinding time, reaching almost $100 \%$ by about $6 \mathrm{~h}$ when the molar ratio of $\mathrm{Ca}$ to $\mathrm{Br}$ is kept constant at 2 .

(4) Radicals are detected in the ground products, due to rupture in the covalent bonds of $\mathrm{C}-\mathrm{C}$ and $\mathrm{C}-\mathrm{Br}$ in HBB.

\section{Acknowledgements}

The authors are grateful to Sumitomo Bakelite Co. Ltd., Japan for supplying the HBB sample and to Dr. Ikoma, Tohoku University, for the kind help with the radical measurement and invaluable discussion.

\section{References}

Atobe, M., Kado, Y., Nonaka, T., 1998. Frequency effect of ultrasound on debromination of stilbene dibromides with zinc powder. Chem. Lett. (7), 699-700.

Bedard, D.L., Van Dort, H.M., 1998. Complete reductive dehalogenation of brominated biphenyls by anaerobic microorganisms in sediment. Appl. Environ. Microbiol. 64, 940947.

Bindra, S.K., Narang, R.S., 1995. Combustion of flame retardants. Chemosphere 31, 4413-4425.

Bindra, S.K., Narang, R.S., 1996. Combustion of flame retardants 2. Chemosphere 33, 1981-1996.

Hall, M., Chen, L., Pandit, C.R., McGimpsey, W.G., 1997. Photo-induced dehalogenation of a-bromoacetylarenes. J. Photochem. Photobiol. A 111 (1-3), 27-33.

Ikoma, T., Ito, O., Tero-Kubota, S., Akiyama, K., 1998a. Twodimensional EPR spectroscopic studies on the radicals in Argonne premium coals. Energy Fuels 12, 996-1000.

Ikoma, T., Ito, O., Tero-Kubota, S., Akiyama, K., 1998b. Hyscore studies on coal radicals. Energy Fuels 12, 13631368.

Ikoma, T., Zhang, Q.W., Saito, F., Akiyama, K., Tero-Kutota, S., Kato, T., 2001. Radicals in the mechanochemical dechlorination of hazardous organochlorine using $\mathrm{CaO}$ nanoparticles. Bull. Chem. Soc. Jpn. 74, 2303-2309.

Khurana, J.M., Sehgal, A., 1996. Chemoselective and stereoselective debromination of vicinal-dibromides with sodium dithionite. Synth. Commun. 26, 3791-3798.

Mackenzie, K., Kopinke, F.D., 1996. Debromination of duroplastic flame-retarded polymers. Chemosphere 33, 24232430.

Raffi, J., Gelly, S., Barral, L., Burger, F., Piccerelle, P., Prinderre, P., Baron, M., Chamayou, A., submitted for publication. Electron paramagnetic resonance of radicals induced in drugs and excipients by radiation or mechanical treatments. Spectrochim. Acta A.

Wanke, T., Vehlow, J., Mark, F.E., Brenner, K.S., 1996. The influence of flame retarded plastic foams upon the formation of $\mathrm{Br}$ containing dibenzo- $p$-dioxins and dibenzofurans in a municipal solid waste incinerator (MSWI). Organohalogen Compd. 28, 530-535. 
Weber, L.W.D., Greim, H., 1997. The toxicity of brominated and mixed-halogenated dibenzo- $p$-dioxins and dibenzofurans: an overview. J. Toxicol. Environ. Health 50 (3), 195-215.

Wei, B., Hor, T.S., 1998. Room-temperature hydrodebromination of $4,4^{\prime}$-dibromobiphenyl catalyzed by $1,1^{\prime}$-bis(diphenylphosphino)ferrocene complexes of palladium. J. Mol. Catal. A: Chem. 132, 223-229.

Zhang, Q.W., Saito, F., Shimme, K., Masuda, S., 1999. Dechlorination of PVC by mechanochemical treatment. J. Soc. Powder Technol. Jpn. 36, 468-473.
Zhang, Q.W., Matsumoto, H., Saito, F., 2001a. Decomposition of polytetrafluoroethylene by grinding with strontium oxide. Chem. Lett., 148-149.

Zhang, Q.W., Lu, J., Saito, F., Baron, M., 2001b. Mechanochemical solid-phase reaction between polyvinylidene fluoride and sodium hydroxide. J. Appl. Polym. Sci. 81, 2249-2252.

Zhang, Q.W., Saito, F., Ikoma, T., Tero-Kubota, S., Hataketa, K., 2001c. Effect of quartz addition on the mechanochemical dechlorination of chlorobiphenyl by using $\mathrm{CaO}$. Environ. Sci. Technol. 35, 4933-4935. 